\title{
Selective Extraction of Palladium(II) with Theophylline Derivatives
}

\author{
Katsuya KAIKAKE and Yoshinari BABA \\ Department of Applied Chemistry, Faculty of Engineering, Miyazaki University, \\ 1-1 Gakuenkibanadainishi, Miyazaki 889-2192, Japan
}

\begin{abstract}
Theophylline derivatives with some kinds of alkyl chains were synthesized and used in extraction experiments involving metal ions. Theophylline derivatives have exhibited a high selectivity for palladium over other precious metals and base metals. The extraction of palladium from acidic chloride media has been investigated using theophylline derivatives $(=$ $\overline{\mathrm{RN}}$ ) as extractants. Palladium(II) was found to be extracted with 7-octyltheophylline according to the following reaction: $\mathrm{PdCl}_{2}+\overline{2 \mathrm{RN}} \rightleftharpoons \overline{\mathrm{PdCl}_{2}(\mathrm{RN})_{2}}$. The extraction equilibrium constant was determined to be $K=2.67 \times 10^{8}\left(\mathrm{~mol} \mathrm{dm}^{-3}\right)^{-2}$. In addition, the stripping of palladium was performed to an extent of $100 \%$ by a single batchwise treatment with a 1.0 mol $\mathrm{dm}^{-3}$ ammonia solution. The stoichiometric relation in the extraction of palladium was supported by an analysis using mass spectrometry.
\end{abstract}

(Received October 2, 2000; Accepted November 22, 2000)

The solvent-extraction process has been attracting much attention as an effective and energy-saving type of separation technique for precious metals. This technique, which has been extensively utilized in the mining industry, is one of the most important processes for the recovery of precious metals from waste water or scraps. Although a number of studies on the solvent extraction of precious metals, such as palladium, have been carried out, most of them have been concerned with synthetic extractants. The separation and purification of precious metals by solvent extraction have been conducted using various types of extractants. Thus far, many extractants have been developed with high selectivity and a high extraction rate. ${ }^{1-5}$

In recent years, however, since the sensational finding of organic compounds, such as endocrine disruptors, we can not also help wondering about the solvent-extraction reagents produced by the petrochemical industry. We have an idea for work from these points of view, such as to make use of a natural compound for a synthetic compound as an extractant. There has been no report that the caffeine skeltone was used as an extractant. Recently, in order to examine the possibility of caffeine as an extractant, we have elucidated the selective extraction equilibrium of palladium(II) with caffeine from acidic chloride media. ${ }^{6}$ However, since caffeine dissolves a little in an aqueous solution, it may not be the most suitable choice as the extractant for palladium. We are now focusing attention on the possibilities to use the caffeine skeltone as the extractant. We have thus picked up theophylline, which is usually contained in coffee and tea, in order to develop a new extractant. Theophylline is applicable to an extraction reagent, since it consists of four nitrogen atoms.

In this work, therefore, alkyl derivatives of theophylline were newly synthesized for lowering their solublility in the aqueous phase. The stoichiometric relation in the extraction of palladium(II) with these extractants was elucidated by examining the effects of chloride ion, hydrogen ion, and the extractant concentrations on its extractability. ${ }^{7}$ Furthermore, the extracted palladium complexes were analyzed by massspectrometry measurements. ${ }^{8,9}$

\section{Experimental}

Reagents

The alkyltheophyllines were synthesized from theophylline in methanol and alkylbromide and potassium carbonate by a conventional method, according to the following reaction: ${ }^{10}$

Theophylline $+\mathrm{R}-\mathrm{Br} \rightarrow \mathrm{R}$-Theophylline $+\mathrm{HBr}$

$\mathrm{R}=$ ethyl, heptyl, hexyl, octyl, decyl, dodecyl.

Alkylbromides with six different alkyl chain lengths (ethyl, hepthyl, hexyl, octyl, decyl and dodecyl) were used to introduce alkylchain to theophylline. Theophylline and alkylbromide were refluxed over potassium carbonate in methanol for $6 \mathrm{~h}$. The final products after purification were obtained as white needle crystals, except for the decyl compound (oily): Rf = 0.11 [ethyl], 0.14[heptyl], 0.37[hexyl], 0.43[octyl], 0.47[decyl], 0.49 [dodecyl] (hexane-ethyl acetate $1: 1$ by volume; TLC; silica gel 60F254); IR $\left(\mathrm{CHCl}_{3}\right) v_{\mathrm{C}-\mathrm{H}} 2929 \mathrm{~cm}^{-1}, v_{\mathrm{C}=\mathrm{O}} 1703,1656 \mathrm{~cm}^{-1}$ $v_{\mathrm{C}=\mathrm{C}} 1548 \mathrm{~cm}^{-1}$ [octyl]; ${ }^{1} \mathrm{H}$ NMR $\left(250 \mathrm{MHz}, \mathrm{CDCl}_{3}, 27^{\circ} \mathrm{C}\right.$, TMS): $\delta(\mathrm{ppm})=0.86\left(3 \mathrm{H}, \mathrm{t}, \mathrm{N}\left(\mathrm{CH}_{2}\right)_{7} \underline{\mathrm{CH}}_{3}\right), 1.28(10 \mathrm{H}, \mathrm{m}$, $\left.\mathrm{NCH}_{2} \mathrm{CH}_{2}\left(\mathrm{CH}_{2}\right)_{5} \mathrm{CH}_{3}\right), 1.89\left(2 \mathrm{H}, \mathrm{m}, \mathrm{NCH}_{2} \mathrm{CH}_{2}\left(\mathrm{CH}_{2}\right)_{5} \mathrm{CH}_{3}\right), 4.31$ $\left(2 \mathrm{H}, \mathrm{t}, \mathrm{NCH}_{2} \mathrm{CH}_{2}\left(\mathrm{CH}_{2}\right)_{5} \mathrm{CH}_{3}\right), 7.66(1 \mathrm{H}, \mathrm{s}$, olefin), $3.38(3 \mathrm{H}, \mathrm{s}$, $\left.\mathrm{N}-\mathrm{Me}_{3}\right), 3.56$ (3H, s, N-Me $)$ [octyl]; ${ }^{13} \mathrm{C} \mathrm{NMR}(62.9 \mathrm{MHz}$, $\left.\mathrm{CDCl}_{3}, \mathrm{TMS}, 27^{\circ} \mathrm{C}\right): \delta(\mathrm{ppm})=22.3,22.6,26.1,27.6,28.7,28.8$, 29.4, 30.6, 31.4, 47.0, 106.6, 140.6, 148.6, 151.4, 154.8, [octyl].

An aqueous solution was prepared by dissolving palladium chloride $\left(1.0 \mathrm{mmol} \mathrm{dm}^{-3}\right)$ in a hydrochloric acid solution. The organic solution was prepared by dissolving alkyl theophyllines $\left(0.1 \mathrm{~mol} \mathrm{dm}^{-3}\right)$ into toluene. The initial $\mathrm{pH}$ was adjusted with a small amount of $1.0 \mathrm{~mol} \mathrm{dm}^{-3}$ hydrochloric acid. 


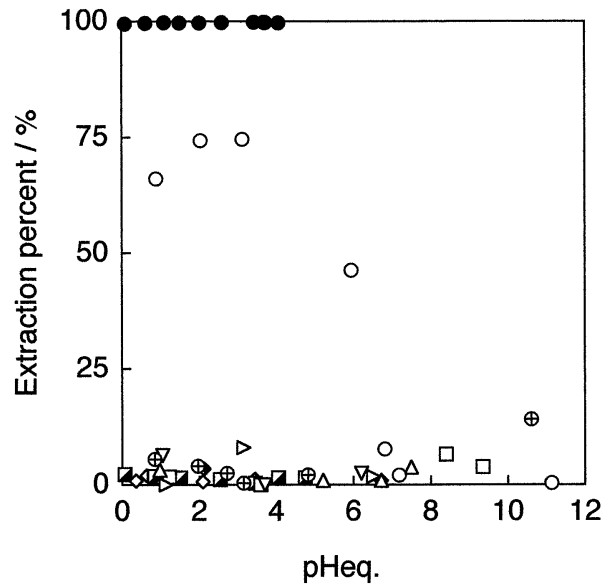

Fig. 1 Effect of the concentration of hydrogen ion on the extraction percent of metal ions with 7-hexyltheophylline. Pd, •; Au, ०; Pt, $\oplus$; $\mathrm{Hg}, \triangle ; \mathrm{Cd}, \nabla ; \mathrm{Zn}, \triangleright ; \mathrm{Co}, \square ; \mathrm{Fe}, \diamond ; \mathrm{Cu}, \mathbf{\square} ; \mathrm{Ni}, \bullet$.

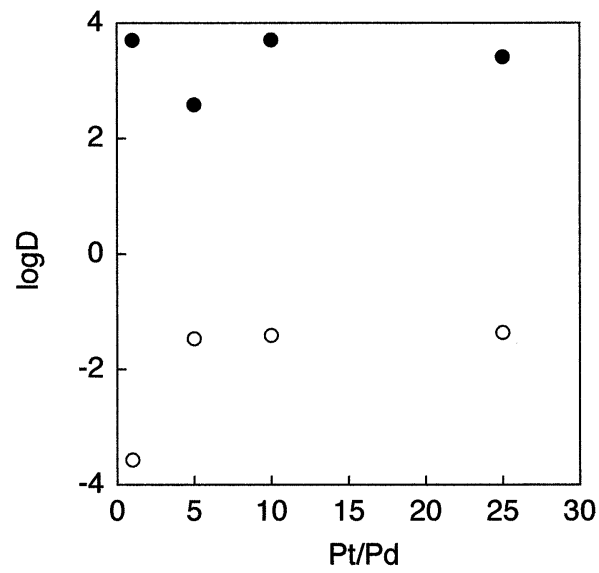

Fig. 2 Selectivity of palladium(II) over platinum(IV) in the extraction from a mixture solution of palladium(II) and platinum(IV). $\mathrm{Pd}, \bullet ; \mathrm{Pt}, \mathrm{O}$.

\section{Extraction and analytical procedure}

All experiments concerning the extraction equilibria were performed by a batchwise method at $303 \mathrm{~K}$. Equal volumes (10 $\mathrm{cm}^{3}$ ) of both phases were mixed in an $\mathrm{L}$ form tube and vigorously shaken with a shaker (TAITEC Co, Ltd., MONOSIN-IIA) at 60 revolutions per minute at $303 \mathrm{~K}$ for 105 h. After phase separation, the $\mathrm{pH}$ and the concentration of palladium(II) in the aqueous solutions were measured by a $\mathrm{pH}$ meter (TOA HM-30S) and atomic adsorption spectrophotometry (HITACHI Co. Z8000), respectively. The palladium(II) content remaining in the organic phase was calculated from the difference between the initial concentration in the aqueous phase and the equilibrium concentration in the aqueous phase.

\section{Preparation of a Pd-alkyltheophylline complex}

In order to investigate the complex composition, the formation of complexes was performed from a water-ethanol system. The organic solution was prepared by dissolving each 7alkyltheophylline $\left(5.0 \mathrm{mmol} \mathrm{\textrm {dm } ^ { - 3 }}\right)$ into an analytical-grade ethanol. The aqueous solution was prepared by $0.1 \mathrm{~mol} \mathrm{dm}^{-3}$ hydrochloric acid containing $0.01 \mathrm{~mol} \mathrm{dm}^{-3}$ palladium(II)

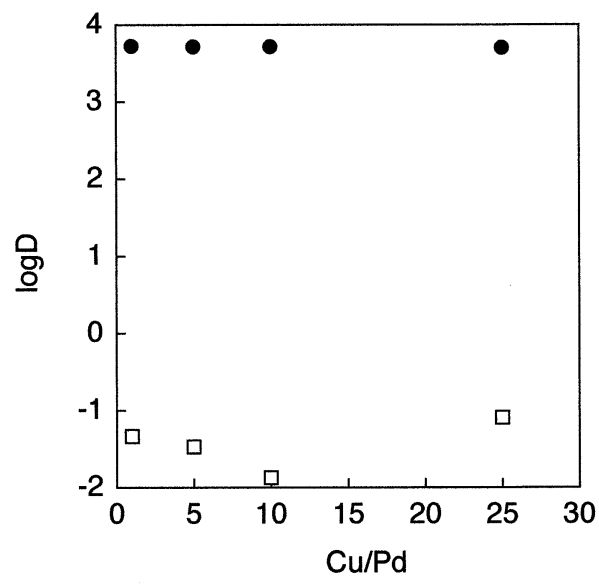

Fig. 3 Selectivity of palladium(II) over copper(II) in extraction from a mixture solution of palladium(II) and copper(II). $\mathrm{Pd}, \bullet$; $\mathrm{Cu}$, $\square$.

chloride. Equal volumes $(25 \mathrm{ml})$ of both solutions were mixed in a $50 \mathrm{ml}$ test tube and shaken. After that, the precipitate formed in the test tube was filtrated and purified by recrystallization with ethanol.

\section{Results and Discussion}

\section{Extraction equilibrium}

In order to determine the time required for extraction equilibrium, palladium(II) was extracted with six kinds of theophylline derivatives in toluene. ${ }^{11}$ Extraction equilibria were reached in approximately $12 \mathrm{~h}$ for all theophylline derivatives, except for the decyl derivatives. Ethyl and heptyl theophylline derivatives formed precipitates in the organic phase. These complexes were hard to dissolve in the organic phase. It was found that the theophylline derivatives with alkyl chain lengths over hexyl are very available as extraction reagents.

\section{Selectivity of metal ions}

Concerning the selectivity of metal ions, the extraction was examined with various metal ions, such as copper(II), nickel(II), cobalt(II), mercury(II), zinc(II), cadmium(II), iron(III), gold(III), platinum(IV), and palladium(II). Among these theophylline derivatives, the extraction of metal ions with 7 hexyltheophylline exhibited a higher selectivity for palladium(II) over base metals and other precious metals, as shown in Fig. 1. Since this extractant exhibited a high selectivity for palladium(II) from acidic chloride media, the stoichiometric relation in the extraction of palladium(II) was investigated in order to elucidate the extracted species of palladium(II).

Furthermore, in order to examine the separation of palladium(II) from a mixture containing other metals, the selective extraction of palladium(II) from a mixture solution containing platinum(IV) or copper(II) was investigated. Palladium(II) was extracted selectively using this extractant from a mixture containing a 25 -fold amount of platinum(IV) or copper(II), as shown in Figs. 2 and 3, respectively. Here, the distribution ratio of palladium(II) is defined by

$$
D=C_{\text {Morg }} / C_{\text {Maq }} \text {, }
$$




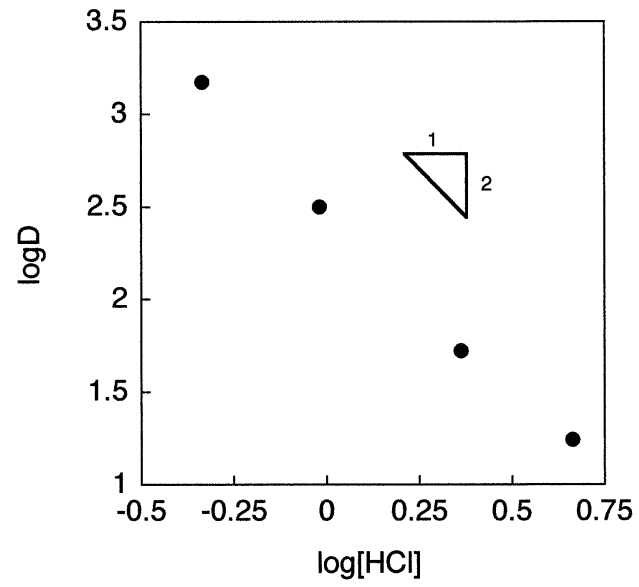

Fig. 4 Effect of the concentration of hydrochloric acid on the distribution ratio of palladium(II) with 7-octyltheophylline. Pd,

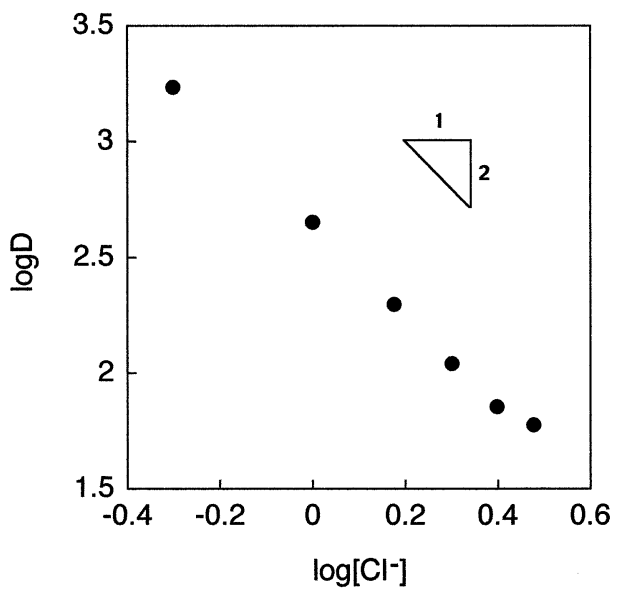

Fig. 5 Effect of the concentration of chloride ion on the distribution ratio of palladium(II) with 7-octyltheophylline. $[\overline{\mathrm{RN}}]=0.1 \mathrm{~mol} \mathrm{dm}^{-3}$; $\mathrm{Pd}$,

where $C_{\text {Morg }}$ and $C_{\text {Maq }}$ are the metal concentrations in the organic and aqueous phase, respectively.

Next, the effect of the concentrations of various chemical species on the distribution ratio was investigated in order to elucidate the stoichiometric relation in the extraction of palladium(II) with 7-octyltheophylline from chloric acidic media.

\section{Effect of the hydrochloric acid concentration}

The effect of the hydrochloric acid concentration on the extraction of palladium(II) was investigated using $0.1 \mathrm{~mol} \mathrm{dm}^{-3}$ 7 -octyl theophylline in toluene as an extractant. Figure 4 shows the effect of the concentration of hydrochloric acid on the distribution ratio of palladium(II), which decreased with increasing the concentration of hydrochloric acid. These plots lie on a straight line with a slope of minus 2. A decrease in the distribution ratio was caused by the formation of a chloride complex anion of palladium(II), which was not extracted with the extractant.

\section{Effect of the chloride-ion concentration}

The effect of the chloride-ion concentration on the extraction of palladium(II) was investigated by keeping the concentration

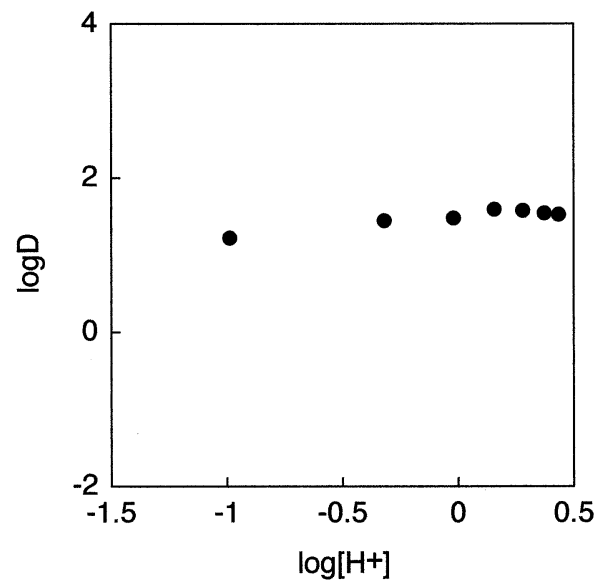

Fig. 6 Effect of the concentration of hydrogen ion on the distribution ratio of palladium $(\mathrm{II})$ with 7 -octyltheophylline. $\left[\mathrm{Cl}^{-}\right]=$ $2.0 \mathrm{~mol} \mathrm{dm}^{-3},[\overline{\mathrm{RN}}]=0.1 \mathrm{~mol} \mathrm{dm} \mathrm{dm}^{-3} . \mathrm{Pd}$,

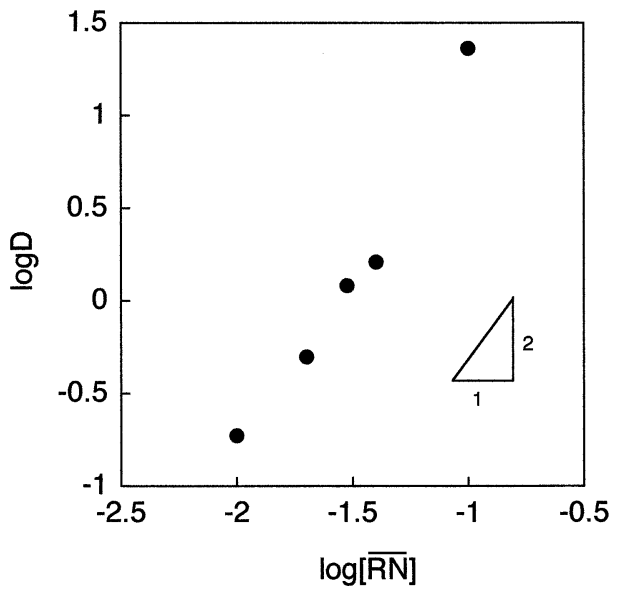

Fig. 7 Effect of the concentration of the extractant on the distribution ratio of palladium(II) with 7-octyltheophylline. $\left[\mathrm{Cl}^{-}\right]=$ $1.0 \mathrm{~mol} \mathrm{dm}^{-3},\left[\mathrm{H}^{+}\right]=0.1 \mathrm{~mol} \mathrm{dm}^{-3}$. $\mathrm{Pd}$,

of the hydrogen ion at $0.1 \mathrm{~mol} \mathrm{dm}^{-3}$. As shown in Fig. 5, a plot of the distribution ratio against the concentration of the chloride ion supplied a linear relationship with a slope of minus 2 in the high-concentration region of the chloride ion.

\section{Effect of the hydrogen-ion concentration}

The effect of the hydrogen-ion concentration on the distribution ratio of palladium(II) was investigated by keeping the chloride-ion concentration at $1.0 \mathrm{~mol} \mathrm{dm}^{-3}$ in the aqueous phase, as shown in Fig. 6. A log-log plot gave a straight line with a slope of 0 , indicating that the hydrogen ion has not participated in the extraction of palladium(II) from hydrochloric acid.

\section{Effect of the extractant concentration}

The effect of the 7-octyltheophylline concentration on palladium(II) extraction was studied at $0.1 \mathrm{~mol} \mathrm{\textrm {dm } ^ { - 3 }}$ hydrochloric acid concentration. The relationship between the distribution ratio and the concentration of extractant is shown in Fig. 7. It can be observed that the extraction of palladium(II) increases along with an increase in the extractant concentration. The slope of the straight line is 2, suggesting that one palladium(II) ion was extracted with two molecules of the 


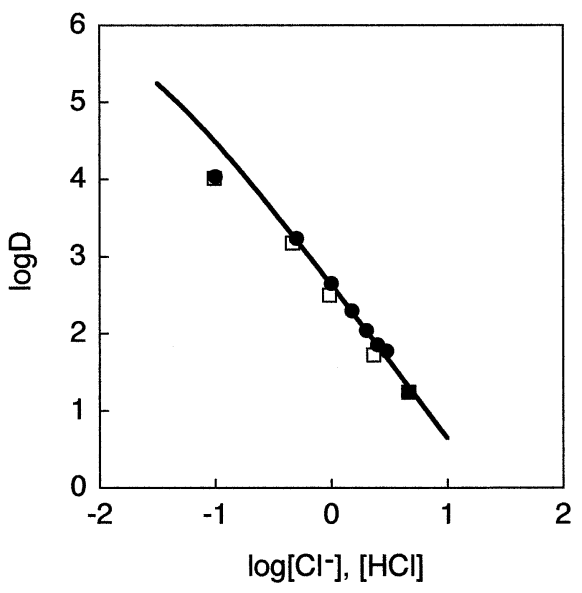

Fig. 8 Effect of the concentration of chloride ion and hydrochloric acid on the distribution ratio of palladium(II) and a theoretical curve. $\left[\mathrm{Cl}^{-}\right], \bullet ;[\mathrm{HCl}], \square ;-$, theoretical curve.

extractant.

Based on the experimental results, as mentioned above, we carried out the following analysis. It is well-known that palladium(II) ions react with chloride ions to form chlorocomplexes in aqueous chloride media. The complexation of palladium(II) was expressed by the following equation: ${ }^{13}$

$$
\begin{aligned}
& \mathrm{Pd}^{2+}+n \mathrm{Cl}^{-} \rightleftharpoons \mathrm{PdCl}_{n}{ }^{2-n}, \\
& \beta_{n}=\frac{\left[\mathrm{PdCl}_{n}^{2-n}\right]}{\left[\mathrm{Pd}^{2+}\right]\left[\mathrm{Cl}^{-}\right]^{n}} .
\end{aligned}
$$

The palladium(II) concentration in an aqueous solution $\left(C_{\text {Maq }}\right)$ was expressed by

$$
C_{\text {Maq }}=\left[\mathrm{Pd}^{2+}\right]\left(1+\sum_{n=1}^{4} \beta_{n}\left[\mathrm{Cl}^{-}\right]^{n}\right)
$$

where $\alpha_{2}$ was defined by

$$
\alpha_{2}=\frac{\left[\mathrm{PdCl}_{2}\right]}{C_{\mathrm{Maq}}}
$$

As can be seen from Figs. 5 and 7, two molecules of 7octyltheophylline $(\overline{\mathrm{RN}})$ react with $\mathrm{PdCl}_{2}$ to form a $2: 1$ extractant: palladium chloride complex, as $\overline{\mathrm{PdCl}_{2}(\mathrm{RN})_{2}}$. The extraction equilibrium was expressed by the following equation: ${ }^{14}$

$$
\mathrm{PdCl}_{2}+\overline{2 \mathrm{RN}} \rightleftharpoons \overline{\mathrm{PdCl}_{2}(\mathrm{RN})_{2}} ; \quad K
$$

where $\overline{\mathrm{RN}}$ stands for the extractant, and the upper-bar indicates the organic phase. The equilibrium relationship of Eq. (3) can be denoted by the following equation from Eq. (1) by considering Eq. (2):

$$
D=\frac{K \beta_{2}\left[\mathrm{Cl}^{-}\right]^{2}[\overline{\mathrm{RN}}]^{2}}{1+\sum_{n=1}^{4} \beta_{n}\left[\mathrm{Cl}^{-}\right]^{n}} .
$$

Equation (4) can be approximated by the following equation at a high-concentration region of the chloride ion:

$$
D \approx \frac{K \beta_{2}\left[\mathrm{Cl}^{-}\right]^{2}[\overline{\mathrm{RN}}]^{2}}{\beta_{4}\left[\mathrm{Cl}^{-}\right]^{4}}
$$

The logarithm of both sides of Eq. (5) was expressed by

$$
\log D=-2 \log \left[\mathrm{Cl}^{-}\right]+\log \frac{K \beta_{2}}{\beta_{4}}+2 \log [\overline{\mathrm{RN}}] .
$$

Figures 5 and 7 were reasonably explained by Eq. (6). The over-all stability constants of the chloro complexes of palladium(II) are known to be $\beta_{1}=5.01 \times 10^{4}\left(\mathrm{~mol} \mathrm{dm}^{-3}\right)^{-1}, \beta_{2}=$ $5.01 \times 10^{7}\left(\mathrm{~mol} \mathrm{dm}^{-3}\right)^{-2}, \beta_{3}=2.00 \times 10^{10}\left(\mathrm{~mol} \mathrm{dm}^{-3}\right)^{-3}$, and $\beta_{4}=$ $7.94 \times 10^{11}\left(\mathrm{~mol} \mathrm{dm}^{-3}\right)^{-4} .{ }^{15}$ The equilibrium constant $(K)$ was obtained by using values of $\beta_{2}$ and $\beta_{4}$ based on Eq. (6) from the value of the distribution in the high-concentration region of the chloride ion (from $1.0 \mathrm{~mol} \mathrm{dm}^{-3}$ to $3.0 \mathrm{~mol} \mathrm{dm}^{-3}$ ). Thus, the extraction equilibrium constant of Eq. (3) was obtained as follows: $K=2.67 \times 10^{8}\left(\mathrm{~mol} \mathrm{dm}^{-3}\right)^{-2}$. Using the value of $K$ and the over-all stability constants, the theoretical curve was calculated based on Eq. (4). The calculated result is shown by the solid line in Fig. 8. The experimental result is in good agreement with the theoretical line. Consequently, the extraction equilibrium of palladium(II) with 7-octyltheophylline was expressed by the Eq. (3).

\section{Stripping}

The stripping characterization is essential to construct the separation and concentration processes of palladium(II) in aqueous solution by the solvent-extraction technique. ${ }^{12}$ The organic solution after extraction was stripped using four

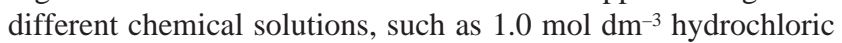
acid, $1.0 \mathrm{~mol} \mathrm{dm}^{-3}$ aqueous ammonia solution, $1.0 \mathrm{~mol} \mathrm{dm}^{-3}$ aqueous thiourea solution and the aqueous mixture solution of $1.0 \mathrm{~mol} \mathrm{dm}{ }^{-3}$ hydrochloric acid and $1.0 \mathrm{~mol} \mathrm{dm}^{-3}$ thiourea. The results of stripping were $1.8 \%, 100 \%, 92.9 \%$ and $93.1 \%$, respectively. In the stripping experiments, the highest stripping percent was obtained using an ammonia solution as the stripping reagent. This is an effective reagent for industrial stripping to recover palladium(II).

\section{Mass spectrum}

In order to confirm the complex formation of palladium(II) with 7-alkyltheophylline, the complex was examined by secondary ion mass spectrometry (SIMS) using ion beams and xenon radiation. A complex of 7-hexyltheophylline, $\mathrm{PdCl}_{2}$ (2:1), was detected as fragment ions of $(\mathrm{M}+\mathrm{H})^{+}$. A molecule of $\mathrm{PdCl}_{2}$ extracted with two molecules of extractant was elucidated by a mass-spectrometric analysis. The resulting complex was analyzed by mass spectrometry (HITACHI Co. M-2000AM) using 3-nitrobenzylalcohol as a matrix. A complex of 7-alkyltheophylline: $\mathrm{PdCl}_{2}$ (2:1) was detected as fragment ions of $(\mathrm{M}+\mathrm{H})^{+}$. The values of $e / z$ of ethyl-, heptyl-, hexyl-, octyl-, decyl-, and dodecyltheophylline: $\mathrm{PdCl}_{2}$ (2:1) were detected as 593, 651, 705, 761,817, 873, respectively. These results have supported the calculated result determined by a slope analysis.

\section{Acknowledgements}

We give great thanks to Dr. Kazuhiro Sugamoto in Miyazaki University for the SIMS measurement.

\section{References}

1. K. Inoue and T. Maruuchi, Hedrometallurgy, 1986, 16, 93. 2. Y. Baba, T. Eguchi, and K. Inoue, Bull. Chem. Soc. Jpn., 
1986, 59, 1321

3. Y. Baba, T. Eguchi, and K. Inoue, J. Chem. Eng. Jpn., 1986, 19,361 .

4. J. Fu, S. Nakamura, and K, Akiba, Sep. Sci. Technol., 1995, 30, 609 .

5. J. Simpson, P. Navarro, and F. J. Alguacil, Hedrometallurgy, 1996, 42, 13.

6. K. Kaikake and Y. Baba, Nippon Kagaku Kaishi, 1999, 6 , 391

7. Y. Baba and K. Inoue, Ind. Eng. Chem. Res., 1988, 27, 1613.

8. M. A. Posthumus, P. G. Kistemaker, and H. L. C Meuzelaar, Anal. Chem, 1978, 50, 985.

9. M. Barber, R. S. Robert, R. D. Sedgwick, and T. N
Andrew, Chem. Commun., 1981, 325.

10. R. G. Manfred and K. R. Louis, J. Org. Chem., 1965, 30 , 3671.

11. K. Inoue, Y. Baba, K. Yoshizuka, and T. Oka, Bull. Chem. Soc. Jpn., 1988, 61, 803.

12. H. Yoshizawa, K. Shiomori, S. Yamada, Y. Baba, Y. Kawano, and K. Kondo, Solvent Extr. Ion Exch., 1997, 4, 157.

13. Y. Baba, K. Inoue, K. Yoshizuka, and T. Furusawa, J. Am Chem. Soc., 1990, 29, 2111

14. Y. Baba, M. Ohshima, and K. Inoue, Bull. Chem. Soc. Jpn., 1986, 59, 3829.

15. I. M. Gel'fman and V. N. Kiseleva, Zn. Neorg. Khim., 1969, 14, 502. 